\title{
A educação ambiental por meio do incentivo da arborização visando ao conforto térmico no Município de Bayeux, Estado da Paraíba, Brasil
}

\section{Yasmin Emanuelle Santos Pereira de Lima ${ }^{1}$, Manuela do Livramento Santos Pereira de Lima ${ }^{2}$, Edielson Gonçalo Gomes ${ }^{3}$}

\author{
${ }^{1}$ Universidade Federal da Paraíba. Centro de Ciências Exatas e da Natureza. \\ Programa de Pós-Graduação em Desenvolvimento e Meio Ambiente. Campus I. João \\ Pessoa-PB, Brasil (CEP 58051-900). E-mail: yasmindelima@gmail.com. \\ ${ }^{2}$ Secretaria de Meio Ambiente do Município de Bayeux. Av. Liberdade, 3720. \\ Centro. Bayeux-PB, Brasil (CEP 58306-001). \\ ${ }^{3}$ Secretaria de Educação do Município de Bayeux. Rua Santa Tereza, 77. SESI. \\ Bayeux-PB, Brasil (CEP 58306-070).
}

Resumo. Trabalhos de educação ambiental que envolvam práticas de arborização na área urbana das cidades são fundamentais para o processo de ensino aprendizagem, formação crítica da população, além de promover o conforto térmico do local. Também auxilia na conservação e recuperação da vegetação nativa em áreas urbanas. Desta forma, este trabalho teve por objetivo conscientizar a população sobre os efeitos positivos da arborização e realização de doações de mudas para sua prática em todo o Município de Bayeux, Estado da Paraíba, Nordeste do Brasil. Tendo como foco a educação ambiental como uma prática de preservação e conservação das espécies e da interdisciplinaridade. 0 trabalho foi executado junto ao Programa Prefeitura nos Bairros. Realizou-se uma pesquisa a respeito de espécies nativas típicas de áreas de Mata Atlântica e frutíferas, posteriormente foram adquiridas mudas de espécies nativas (ipê branco Tabebuia roseo-alba, ipê rosa Handroanthus heptaphyllus e cumaru Dipteryx odorata) e cinco tipos de frutíferas (graviola Annona muricata, goiaba Psidium guajava, caju Anacardium occidentale, pinha Annona squamosa e acerola Malpighia emarginata), que foram doadas, após realização de palestras de conscientização da importância da arborização nos bairros e na cidade em geral, em 12 escolas municipais de ensino fundamental. Ao todo foram doadas 630 mudas. Conclui-se que através de práticas interdisciplinares houve a educação ambiental com cidadãos do município, para a preservação das espécies e promoção de conforto térmico trazendo qualidade de vida.

Palavras-chave: Mudas nativas; Mata Atlântica; Conservação; Gestão municipal; Mudança climática.

Abstract: Environmental education through the encouragement of afforestation for thermal comfort in
Recebido: 06/08/2018

Aceito: $30 / 08 / 2018$

Publicado: $31 / 08 / 2018$

Acesso aberto

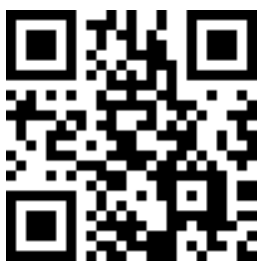

ORCID

(D) 0000-0002-2132-0164

Yasmin Emanuelle

Santos Pereira de Lima

(D) 0000-0003-4419-1462

Manuela do

Livramento Santos

Pereira de Lima

D 0000-0002-6499-330X

Edielson Gonçalo

Gomes 
Bayeux, State of Paraíba, Brazil. Environmental Education works involving urbanization practices in the urban area of the cities are fundamental for the process of teaching learning, critical formation of the population, besides promoting the thermal comfort of the place. It also assists in the conservation and recovery of native vegetation in urban areas. The objective of this work was to raise awareness among the population about the positive effects of afforestation and the donation of seedlings for their practice in the entire Municipality of Bayeux, State of Paraíba Northeast Brazil. Focusing on environmental education as a practice of preservation and conservation of species and interdisciplinarity. The work was executed together with the City Hall Program in the Neighborhoods. A study was carried out on native species typical of Atlantic and fruit forest areas, followed by seedlings of three native species (ipê branco Tabebuia roseoalba, ipê rosa Handroanthus heptaphyllus and cumaru Dipteryx odorata) and five types of fruit trees (soursop Annona muricata, guava Psidium guajava, cashew Anacardium occidentale, pineapple Annona squamosa and Barbados cherry Malpighia emarginata), which were donated, after lectures to raise awareness of the importance of afforestation in the neighborhoods and in the city in general, in 12 municipal primary schools. In all, 630 seedlings were donated. It was concluded that through interdisciplinary practices there was environmental education with citizens of the municipality, for the preservation of species and the promotion of thermal comfort bringing quality of life.

Keywords: Native changes; Atlantic Forest; Conservation; Municipal management; Climate change.

\section{Introdução}

A sociedade atual necessita de novos caminhos e novas percepções que possam orientar novas ações surge assim também a necessidade de conhecermos e adquirir novos hábitos. Morin (2007) ressalta que precisamos pensar que fazemos parte desse planeta, dessa era planetária, Leff (2001), mostra-nos a complexidade ambiental na perspectiva de uma relação ser humano/Natureza que tem por base a ética e as diferenças. Considerando a perpetuação das sociedades humanas, é preciso que as atividades e as atitudes sejam viáveis economicamente. Nesta visão constatamos que precisamos de uma sociedade educada.
A mudança de paradigma social leva a transformar a ordem econômica, política e cultural, o que é impensável sem uma transformação da consciência e comportamentos. Nesse sentido a educação converte se num processo estratégico para o propósito de formar os valores, habilidade e capacidade para orientar a transição para a sustentabilidade (Leff, 2001, p. 23).

Partindo desta conjuntura, a escola é o ambiente para se reconhecer os problemas ambientais e as possibilidades de revê-los e mitigá-los. É neste local que parte da população encontra-se (Santos et al., 2017). Na escola adquirimos conhecimentos, fazemos amizades 
e partilhamos no nosso cotidiano com quem convivemos.

As diversas formas de estar no mundo criam nossas ações, que constroem possibilidades e produzem cuidados com o outro, com a Natureza, para que possamos compreender que o meio ambiente é o todo, e o mundo somos nós. A educação contribui para este novo olhar, trazendo valores para o cotidiano, uma postura de sentir-se parte $\mathrm{e}$ integrante do planeta.

Portanto, a temática abordada neste trabalho é a educação para a mobilização socioambiental. A educação ambiental, que surge como política pública no Brasil a partir da Lei no 9.795/1999, que dispõe sobre a Política Nacional de Educação Ambiental (PNEA), apresenta e propõem ações e práticas educativas voltadas à sensibilização da sociedade sobre as questões ambientais (Brasil, 1999), e com esse sentido ético, buscam sujeitos conscientes e cidadãos.

A explosão demográfica é uma questão iniludível na perspectiva da sustentabilidade. A população mundial chegará a mais de seis bilhões antes do término do século XX e poderia alcançar oito bilhões e 500 milhões até o ano de 2025 (Leff, 1999). Carlos (1997) afirma que se deve lembrar que a cidade tem a dimensão do humano refletindo-se e reproduzindo-se através do movimento da vida, de um tempo específico que tem na base o processo de construção humana.

A seleção do Município de Bayeux como estudo de caso deu-se em décorrência de suas características sociais e geográficas e da necessidade de aplicação dos conceitos e teorias analisados, para melhoria das condições de vida em equilíbrio com o meio ambiente em áreas de interesse social fragilizadas. Segundo Lima (2018) a cidade, como parte de uma região metropolitana de grande dispersão e crescimento demográfico pós 1970, apresenta problemas recorrentes na maioria das cidades brasileiras, cujo planejamento urbano tornou-se fragmentado em relação ao território e de pouca articulação técnica e conceitual.
Segundo Santos (2017), Bayeux apresenta alterações no seu campo térmico com resultados que apontam para cuidados específicos em alguns setores da cidade. Os bairros de Tambay e SESI apresentam os resultados mais críticos, no que diz respeito às elevadas temperaturas com a formação de ilhas de calor e consequentemente desconforto térmico. Esta realidade sugere urgência na implantação de medidas que visem ao planejamento urbano e ambiental da cidade (Santos, 2017).

Além disso, a escolha desse projeto para o município foi devido à densidade demográfica com adensamento populacional, condição ambiental e sem a percepção de árvores no município e a população desconhecer os serviços ambientais que as proporcionam as pessoas, apesar do município contar com uma reserva de Mata Atlântica, o Parque Estadual Mata do Xém-Xém, com 189 ha e rodeado de manguezais.

Porém, os dois importantes dispositivos de amenização climática no município de Bayeux, a Mata do Xém-Xém e o manguezal, em torno do ambiente urbano, não são suficientes para proporcionar a melhoria climática da cidade, que apresenta excesso de material de recobrimento impermeável e baixo albedo, além da má distribuição da cobertura vegetal no espaço intraurbano da malha urbana. Desta forma, são necessárias medidas urgentes no que tange à arborização urbana e sua distribuição (Santos, 2017).

A educação ambiental, sendo assim, uma estratégia de apoio para a conscientização, bem como a importância das árvores no conforto ambiental e bem-estar da população, além de estimular o sentimento de pertencimento ao meio ambiente, como parte integrante do mesmo universo.

No desenvolvimento do trabalho buscamos despertar o interesse da comunidade para o problema da falta de árvores no município, sensibilizando a comunidade no interesse de cuidar do 
meio ambiente sentindo se parte integrante do mesmo.

\section{Materiais e métodos}

\section{Caracterização da área}

A área de estudo foi o Município de Bayeux-PB. Especificamente a distribuição das mudas ocorreram em 12 escolas municipais: a Escola Municipal de Ensino Fundamental (E.M.E.F.) Assis Chateaubriand, E.M.E.F. Berenice Ribeiro Coutinho, E.M.E.F. Fernando Cunha Lima, E.M.E.F. Flávio Ribeiro Coutinho, E.M.E.F. Jaime Caetano, E.M.E.F. João Jacinto, E.M.E.F. Joaquim de Brito, E.M.E.F. Joaquim Lafayette, E.M.E.F. José Ribeiro de Morais, E.M.E.F. Moacir Dantas, E.M.E.F. Pascoal Massílio.

\section{Procedimentos metodológicos}

O Projeto Prefeitura nos Bairros é um projeto que tem a finalidade de trazer alguns serviços oferecidos pela prefeitura para mais próximo do cidadão. Com isso, as ações do projeto eram realizadas nas escolas municipais dos bairros. Semanalmente a ação estava em um bairro diferente, em um total de 12 bairros foram contemplados com 0 projeto.
A Secretaria Municipal de Meio Ambiente de Bayeux participou do projeto com a iniciativa de arborização da cidade, onde a ideia era "adote uma árvore", esperando que os cidadãos do bairro adotasse uma muda e plantasse no canteiro público ou em uma área particular e fizesse o acompanhamento do crescimento da árvore.

$\mathrm{Na}$ ação de distribuição das mudas, foram feito palestras sobre temas voltados a arborização em geral, como corte, poda, manutenção e orientação de como plantas as mudas. Em seguida os cidadãos escolhiam o tipo de muda, nativa ou frutífera, através de orientação da equipe levando em consideração o local que seria plantado a muda e suas características.

Através da doação da ONG AFINK, obteve-se mudas nativas e frutíferas. As mudas foram representadas por três espécies nativas (ipê branco Tabebuia roseo-alba, ipê rosa Handroanthus heptaphyllus e cumaru Dipteryx odorata), bem como por cinco frutíferas (graviola Annona muricata, goiaba Psidium guajava, caju Anacardium occidentale, pinha Annona squamosa e acerola Malpighia emarginata).

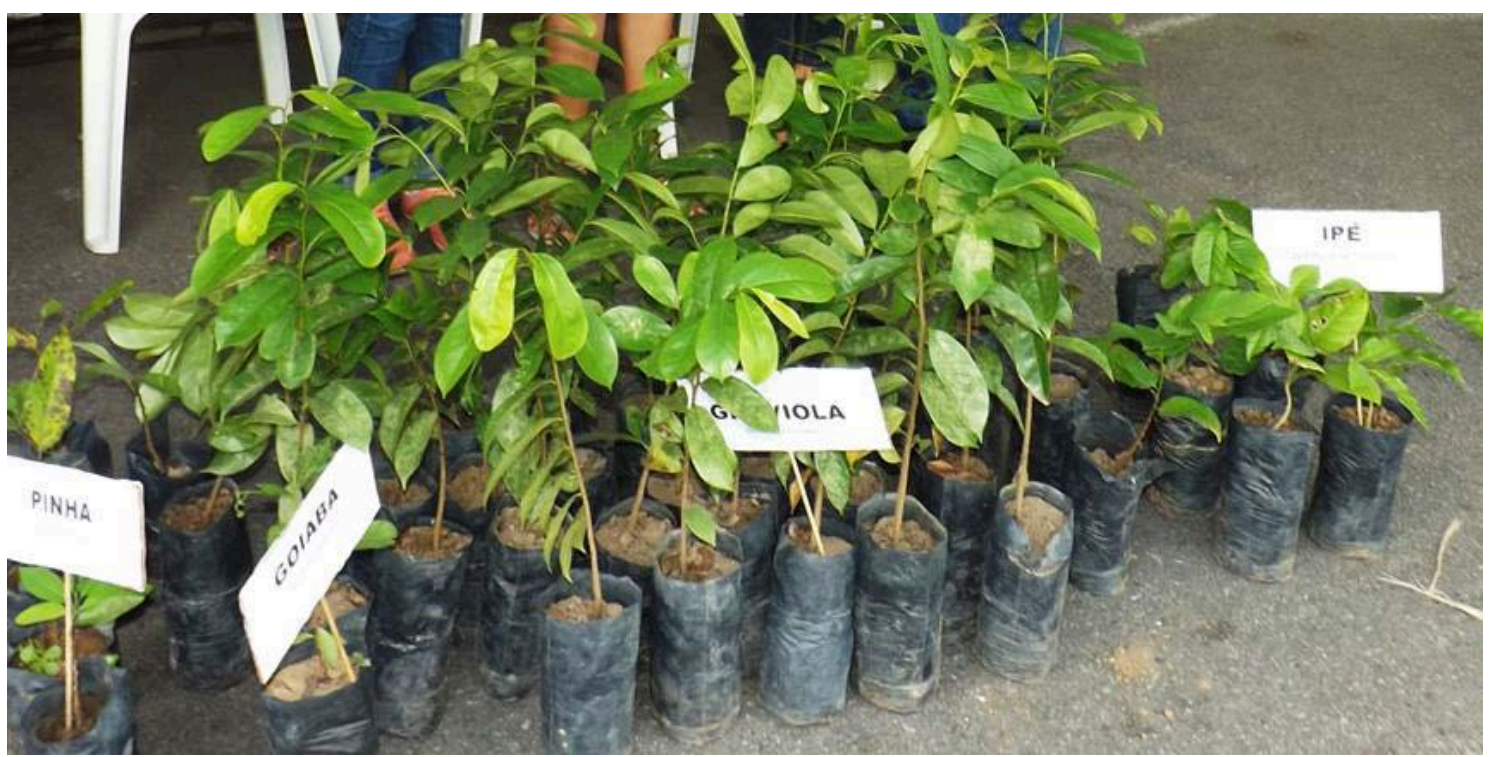

Figura 1. Mudas expostas na ação Prefeitura nos Bairros. 


\section{Resultados e discussão}

Participaram do Projeto Muda 12
escolas municipais do ensino
fundamental, onde foram distribuídas
630 mudas catalogadas (Tabela 1), para
os resultados qualitativos observa-se que
a metodologia transdisciplinar, ao
possibilitar a superação de um

paradigma tradicional, levando a conscientização e ajudando a comunidade escolar e do bairro a entender que a vida no planeta tem relação direta com a permanência das árvores, devido a seus benefícios, auxiliando na conservação de um ambiente equilibrado.

Tabela 1. Espécies utilizadas para arborização de Bayeux-PB.

\begin{tabular}{lcc}
\hline Nome científico & Nome popular & Quantidade \\
\hline Tabebuia roseo-alba & Ipê Branco & 60 \\
Handroanthus heptaphyllus & Ipê Rosa & 60 \\
Dipteryx odorata & Cumarú & 60 \\
Annona muricata & Graviola & 90 \\
Psidium guajava & Goiaba & 90 \\
Anacardium occidentale & Caju & 90 \\
Annona squamosa & Pinha & 90 \\
Malpighia emarginata & Acerola & 90 \\
\hline Total & & $\mathbf{6 3 0}$ \\
\hline
\end{tabular}

A população respondeu de forma positiva ao projeto, grande parte das que participaram da ação adotaram uma muda (Figura 2). As pessoas que receberam mantiveram um diálogo de entusiasmo, relatando e trocando experiências dos benefícios de algumas plantas, mostrando-se incentivada em manter e acompanhar o desenvolvimento das mudas que seriam levadas para suas residências ou canteiros públicos próximos.

Foi possível observar que a população teve certa resistência em escolher as mudas de árvores nativas, elas preferiam as árvores frutíferas. Com isso, a equipe tentou conscientizar sobre a importância da preservação das espécies nativas.

A promoção dos encontros entre a comunidade escolar e órgãos ambientais para discutir as diversas situações ambientais no município de Bayeux. Fizeram parte do nosso trabalho de sensibilização para que assim pudessemos despertar, entendermos e termos um pensamento sistêmico, e assim considerar que vivemos em sistemas interdependentes ecológicos e sociais.

Através das palestras, a população pôde entender a problemática ambiental seja de uma solicitação para poda ou corte de uma árvore quando plantada em local inadequado, a legislação e o cumprimento das leis. Como também, ter conhecimento sobre os benefícios das árvores próximo as suas residências.

\section{Conclusão}

Este trabalho teve como resultado a doação de 630 mudas, dentre elas cinco espécies frutíferas e três espécies nativas com a finalidade de arborização da área urbana do Município de Bayeux.

A ação de educação ambiental, promovida pelo órgão municipal, atendeu a finalidade de conscientizar a população sobre a importância da arborização nos bairros, para um conforto térmico e melhor qualidade de vida da população e a preservação dos recursos naturais. 
Teve como resultado o aprimoramento da relação entre o homem e a natureza, sendo em especial a educação ambiental a levar os envolvidos o respeito mútuo, para assim entender a problemática ambiental seja de uma solicitação para poda ou corte de uma árvore quando plantada em local inadequado, respeitando assim a legislação e o cumprimento das leis. Conclui-se que a ação de arborização desenvolvida é uma maneira eficaz de sensibilização desenvolvida através da educação ambiental, preservando e conservando os recursos naturais.

\section{Conflito de interesses}

Os autores declaram não haver conflito de interesses.

\section{Referências}

Brasil. Lei no 9.795, de 27 de abril de 1999. Dispõe sobre a educação ambiental, institui a Política Nacional de Educação Ambiental e dá outras providências. Disponível em: <http://www.planalto.gov.br/CCIVil_03/LEI S/L9795.htm>. Acesso em: 23 abr. 2018.

Carlos, A. F. A. A cidade. 3. ed. São Paulo: Contexto, 1997.
Leff, E. Educação ambiental e desenvolvimento sustentável. In: Reigota, M. (Org.). Verde cotidiano, o meio ambiente em discussão. Rio de Janeiro: DP\&A, 1999.

Leff, E. Saber ambiental: sustentabilidade, racionalidade, complexidade, poder. Petrópolis: Vozes/PNUMA, 2001.

Lima, Y.E. S. P. A implementação de ZEIS em áreas de preservação no Município de Bayeux-PB e suas implicações socioambientais. João Pessoa: Universidade Federal da Paraíba, 2018. (Dissertação de mestrado).

Morin, E. 0 método. 6. ed. Porto Alegre: Sulina, 2007.

Santos, A.; Lima, M. L. B.; Maciel, L. M. N. L.; Paz, M. C. P.; Paz, R. J. A interdisciplinaridade na educação ambiental em escolas públicas: concepções e ações. Educação Ambiental em Ação, n. 61, 2017. Disponível em: <http://www.revistaea.org/artigo.php?idarti go $=2871>$. Acesso em: 23 abr. 2018.

Santos, E. C. A. Clima urbano e a sua relação com o uso e cobertura do solo na Cidade de Bayeux - Paraíba: subsídio ao planejamento e a gestão ambiental. João Pessoa: Universidade Federal da Paraíba, 2017. (Dissertação de mestrado). 